

\title{
Co-infection with influenza-associated acute respiratory distress syndrome requiring extracorporeal membrane oxygenation
}

Sacha Rozencwajg, Nicolas Brechot, Matthieu Schmidt, Guillaume Hékimian, Guillaume Lebreton, Sébastien Besset, Guillaume Franchineau, Ania

Nieszkowska, Pascal Leprince, Alain Combes, et al.

\section{To cite this version:}

Sacha Rozencwajg, Nicolas Brechot, Matthieu Schmidt, Guillaume Hékimian, Guillaume Lebreton, et al.. Co-infection with influenza-associated acute respiratory distress syndrome requiring extracorporeal membrane oxygenation. International Journal of Antimicrobial Agents, In press, 10.1016/j.ijantimicag.2017.11.005 . hal-01653427

\section{HAL Id: hal-01653427 https://hal.sorbonne-universite.fr/hal-01653427}

Submitted on 1 Dec 2017

HAL is a multi-disciplinary open access archive for the deposit and dissemination of scientific research documents, whether they are published or not. The documents may come from teaching and research institutions in France or abroad, or from public or private research centers.
L'archive ouverte pluridisciplinaire HAL, est destinée au dépôt et à la diffusion de documents scientifiques de niveau recherche, publiés ou non, émanant des établissements d'enseignement et de recherche français ou étrangers, des laboratoires publics ou privés. 
Original article

\section{Co-infection with influenza-associated acute respiratory distress syndrome requiring extracorporeal membrane oxygenation}

Sacha Rozencwajg ${ }^{1,2}$, Nicolas Bréchot ${ }^{1}$, Matthieu Schmidt ${ }^{1,2}$, Guillaume

Hékimian ${ }^{1}$, Guillaume Lebreton ${ }^{3}$, Sébastien Besset ${ }^{1}$, Guillaume Franchineau ${ }^{1}$, Ania

Nieszkowska ${ }^{1}$, Pascal Leprince ${ }^{3}$, Alain Combes ${ }^{1,2}$, Charles-Edouard Luyt ${ }^{1,2}$

1) Service de Réanimation, Groupe Hospitalier Pitié-Salpêtrière, Assistance PubliqueHôpitaux de Paris, Paris, France

2) Sorbonne Universités, UPMC Université Paris 06, INSERM, UMRS-1166, ICAN Institute of Cardiometabolism and Nutrition, Paris, France

3) Service de Chirurgie Thoracique et Cardiovasculaire, Institut de Cardiologie, Groupe Hospitalier Pitie-Salpêtrière, Assistance Publique-Hôpitaux de Paris, Paris, France

Running title: Co-infection with influenza-related ARDS requiring ECMO

Corresponding author: Pr Charles-Edouard Luyt, MD, PhD, Service de Réanimation, Institut de Cardiologie, Hôpital de la Pitié-Salpêtrière, 47, bd de l’Hôpital, 75651 Paris Cedex 13, France. Tel: +33 (0)1 421638 24; Fax: +33 (0)1 42 163817

E-mail address: charles-edouard.luyt@aphp.fr 


\section{ABSTRACT}

Co-infection frequency and impact among influenza-associated acute respiratory distress syndrome (ARDS) patients requiring extracorporeal membrane oxygenation (ECMO) are not known. This retrospective, observational analysis concerned data prospectively collected from patients admitted to our medical intensive care unit (ICU) who received ECMO support for influenza-associated ARDS between 2009 and 2016. Co-infection was defined as occurring within 48 hours following ICU admission. Among the 77 ARDS patients requiring ECMO support, 39 (51\%) developed co-infections, with Staphylococcus aureus (18 (46\%) of the co-infected) being the most prevalent pathogen. Panton-Valentin leukocidin (PVL)-producing $S$. aureus was isolated from ten patients (56\% of S. aureus co-infections and $26 \%$ of all co-infections). Except for body mass index, initial disease severity and antibiotic treatment prior to admission, patients with co-infection were comparable to those without. Co-infection was associated with higher in-ICU mortality (62\% vs. 29\% without; $\mathrm{p}=0.006$ ), and, on day 60, (median [interquartile range]) fewer ECMO-free days (0 [0-19] vs. 23 [0-46]; p=0.004) and fewer mechanical ventilation-free days (0 [0-0] vs. 6 [0-35]; $p=0.003)$. Multivariable analyses retained age $>49$ years, preECMO Simplified Acute Physiology Score II >70 and co-infection as independent predictors of hospital mortality. In conclusion, co-infection is frequent in ECMOtreated patients with influenza-associated ARDS, affecting 50\% of them, and is independently associated with poor outcome. S. aureus was the most frequently identified pathogen, with a high rate of PVL-positive S. aureus. Whether specific therapy targeting PVL-producing S. aureus should be given remains to be determined. 
Keywords:

Acute respiratory distress syndrome

Bacterial and/or fungal co-infection

Extracorporeal membrane oxygenation

Influenza

Panton-Valentine leukocidin

Staphylococcus aureus

Abbreviations:

ECMO; extracorporeal membrane oxygenation. ARDS; acute respiratory distress syndrome. ICU; intensive care unit. TA; tracheal aspirate. BAL, bronchoalveolar lavage. VV-ECMO; venovenous-ECMO. VA-ECMO; venoarterial extracorporeal membrane oxygenation . VAV-ECMO; venoarterialvenous - extracorporeal membrane oxygenation. APRV, airway pressure-release ventilation. MV, mechanical ventilation. SAPS; simplified acute physiology score. SOFA; sequential organ-failure assessment. PVL; Panton-Valentin leukocidin. $\mathrm{PaO}_{2} / \mathrm{F}_{\mathrm{I}} \mathrm{O}_{2}$; partial oxygen pressure in arterial blood/fraction of inspired oxygen ratio. 


\section{Introduction}

Extracorporeal membrane oxygenation (ECMO) is a therapeutic option for severe acute respiratory distress syndrome (ARDS) refractory to conventional treatment $[1,2]$. Mortality of patients with influenza-associated ARDS requiring ECMO is lower than that for patients with ARDS of other causes [3] and survivors' long-term outcomes are relatively good [4-6]. Thus, these patients are considered privileged candidates for early ECMO initiation. Nevertheless, their mortality remains high, ranging between 35\% and 45\% [3,7]. Their specific risk factors for death are still debated; particularly, the role of bacterial and/or fungal co-infection remains uncertain [8]. Although a recent large study found co-infection to be associated with increased risk of death for patients with influenza-associated pneumonia [9], data for severe influenza-associated ARDS requiring ECMO are lacking. Therefore, we undertook this study to describe the frequency of microbial co-infections patients admitted to our intensive care unit (ICU) for influenza-related ARDS requiring ECMO, and their clinical features, risk factors for mortality and outcomes, hypothesizing that initial co-infection would increase their morbidity and mortality.

\section{Methods}

\subsection{Population}

All patients admitted to our 26-bed, tertiary-care ICU from 2009 to 2016 who received ECMO support for influenza-associated ARDS were included. ARDS was defined as "influenza-associated" when the following criteria were met: 1) seasonal 
epidemic; 2) compatible symptoms (i.e., fever, cough, shortness of breath and myalgias); 3) influenza infection confirmed by positive reverse-transcriptase polymerase chain reaction on a nasal swab or lung secretion sample (tracheal aspirate (TA), bronchoalveolar lavage (BAL), and 4) ARDS satisfying the Berlin criteria, i.e., onset $<7$ days, bilateral radiological opacities and respiratory failure with partial oxygen pressure in arterial blood/fraction of inspired oxygen ratio $\left(\mathrm{PaO}_{2} / \mathrm{F}_{\mathrm{I}} \mathrm{O}_{2}\right)<300 \mathrm{~mm} \mathrm{Hg}$ with positive end-expiratory pressure (PEEP) $>5 \mathrm{~cm} \mathrm{H}_{2} \mathrm{O}$ not fully explained by cardiac failure or fluid overload [10]. Venovenous-ECMO (VV-ECMO) was implanted according to international recommendations $[2,11]$ in the case of sustained refractory hypoxemia $\left(\mathrm{PaO}_{2} / \mathrm{F}_{\mathrm{I}} \mathrm{O}_{2}<80 \mathrm{~mm} \mathrm{Hg}\right)$, uncompensated hypercapnia ( $\mathrm{pH}<7.15$ ) and/or impossibility to maintain a protective-lung ventilation strategy (i.e., high end-inspiratory plateau pressure $>30 \mathrm{~cm} \mathrm{H}_{2} \mathrm{O}$ despite optimal mechanical ventilation settings). Venoarterial (VA)- or venoarterialvenous (VAV)ECMO was initiated for ARDS associated with right ventricular dysfunction, uncontrolled septic shock with high-dose catecholamines or myocarditis. Patients with influenza-related myocarditis without ARDS criteria were excluded.

\subsection{Ventilatory management during ECMO support}

During ECMO, an ultraprotective ventilation strategy was applied: the airway pressure-release ventilation (APRV) mode was used, with the upper and lower pressure levels set, respectively, at 24 and $12 \mathrm{cmH}_{2} \mathrm{O}$. Respiratory rate was initially set at 20 breaths/min, then adjusted according to blood gases and ECMO settings. ECMO parameters $\left(\mathrm{F}_{\mathrm{I}} \mathrm{O}_{2}\right.$ and sweep-gas flow) were set to obtain pulse-oximetrymeasured peripheral blood-oxygen saturation $>88 \%$ (or $\mathrm{PaO}_{2}>60 \mathrm{mmHg}$ ) and 
$\mathrm{PaCO}_{2}$ between 36 and $44 \mathrm{mmHg}$ [12]. Neuromuscular blockade was continued, if needed (decided by the treating physician), for 48 hours. ECMO weaning followed the Extracorporeal Life Support Organization protocol: sweep-gas flow on ECMO membrane was set at $0 \mathrm{~L} / \mathrm{min}$ during 24 hours, with APRV mode maintained or switched to volume-controlled mode and tidal volume set at $6 \mathrm{~mL} / \mathrm{kg}$ of predicted body weight. If the patient tolerated this ventilation strategy, with no increase of plateau pressure $>30 \mathrm{cmH}_{2} \mathrm{O}$, and blood gases showed normocapnia and $\mathrm{PaO}_{2} / \mathrm{F}_{\mathrm{I}} \mathrm{O}_{2}$ $>80$ mmHg, ECMO was removed. Once ECMO was withdrawn, mechanical ventilation (MV) was pursued with a protective ventilation strategy and daily sedation assessment according to our sedation protocol.

\subsection{Co-infection definitions}

Co-infection was defined as occurring within 48 hours following ICU admission. Bacterial co-infection required one of the following criteria: 1) lung-secretion-sample culture positive (i.e. $>10^{5} \mathrm{CFU} / \mathrm{mL}$ for TA and $>10^{4} \mathrm{CFU} / \mathrm{mL}$ for BAL) for a bacterial pathogen; 2) blood culture positive for a known pneumonia-causing agent (e.g., Streptococcus pneumonia, Staphylococcus aureus, ...) or 3) serology/blood-antibody test positive (i.e., IgM detection or four-fold IgG increase within 1 week) for a known pneumonia-causing pathogen (e.g., Mycoplasma pneumoniae or Legionella pneumophila). Fungal co-infection had to satisfy one of the following criteria: lungsecretion-sample culture positive for fungus other than Candida species; direct lungsecretion-sample examination positive for Pneumocystis jirovecii using immunofluorescence or blood sample positive for Aspergillus fumigatus antigenemia.

A secondary analysis was conducted on patients without bacteriologically 
confirmed co-infection who received antibiotics prior to bacteriological sampling; they were divided into those with a "high" or "low" probability of being co-infected. We then compared patients co-infected or with a high probability of co-infection vs. patients not infected or with low probability of co-infection (see Supplementary material).

\subsection{Data collection}

The following parameters were collected: co-morbidities, Simplified Acute Physiology Score (SAPS) II; Sequential Organ-Failure Assessment (SOFA) score; pre-ECMO ARDS management, including ventilator settings, plateau pressure, adjuvant therapies (i.e., prone positioning, nitric oxide use, neuromuscular blockade); ICU length of stay; and in-hospital survival. Data were retrieved from other hospitals’ medical charts when ECMO had been implanted by our mobile team. ECMO cannulation (i.e., VV, VA or VAV configuration), duration and related complications were also recorded $[13,14]$.

We also retrieved relevant influenza-infection information: dates of first symptoms and diagnosis confirmation, influenza genotype and subtype, and when neuraminidase inhibitors were stared. Antibiotics given before hospital admission and at the time of diagnosis were also noted.

\subsection{Ethics}

In accordance with the ethical standards of our hospitals' institutional review board (Committee for the Protection of Human Subjects) and French law, informed consent 
for demographic, physiological and hospital-outcome data analyses was not required because this observational study did not modify existing diagnostic or therapeutic strategies. However, patients and/or relatives were informed of the anonymous data collection and told they could decline inclusion. The National Commission for Informatics and Liberties (CNIL) approved this study (no. 1950673).

\subsection{Statistical analyses}

Continuous variables, expressed as mean ( \pm standard deviation, SD) or median [interquartile range, IQR], were compared using Student's $t$-test or Wilcoxon's rank test. Categorical variables, expressed as number (\%), were compared with $\chi^{2}$ tests. Patients’ demographic and clinical characteristics and laboratory findings were examined in univariable analyses for association with hospital mortality. Continuous variables were transformed into categorical variables (by defining the best thresholds after analyzing mortality in each corresponding variable quartile). Thereafter, multiple logistic regression analyses using backward, stepwise variable elimination were run (variable exit threshold $\mathrm{p}>0.05$ ). Factors achieving $\mathrm{p} \leq 0.10$ in our univariable analyses and parameters previously reported to be strongly associated with death were entered into the multivariable model. All potential explanatory variables included in the multivariable analyses were subjected to collinearity analysis with a correlation matrix. Variables associated with one another were not included in the model. Model goodness-of-fit was assessed with the determination coefficient $\left(R^{2}\right)$, with $\mathrm{p}<0.05$ defining statistical significance. Analyses were computed with Statview v5.0 (SAS Institute Inc., Cary, NC, USA). 


\section{Results}

\subsection{Study population}

Among the 116 admitted to our ICU with an influenza diagnosis between October 2009 and May 2016, 89 were implanted with ECMO and the 77 with influenzaassociated ARDS were included in this study. Twelve patients were excluded from the analysis: ten received VA-ECMO for acute myocarditis (no ARDS), one had ARDS unrelated to influenza and another nosocomial influenza diagnosed while on

ECMO (Figure 1). Their characteristics are summarized in Table 1 and

Supplementary Table S1. Although patients were young and had few comorbidities, they were severely ill, as assessed by their high initial SAPS II and SOFA scores. The VV-ECMO configuration was used most often (75\%), with 88\% implanted by our institution’s Mobile Circulatory Assistance Unit surgeon, at a median [IQR] of 2 [1-8] days between MV start and ECMO implantation. The most frequent ARDS rescue therapies prior to ECMO were neuromuscular blockers, nitric oxide and prone positioning.

\subsection{Co-infection}

Influenza A serotype predominated, 97\% being subtype 2009v(H1N1) (Table 1). Thirty-nine (51\%) patients developed co-infections, with S. aureus (18 patients [46\%]) being the most common pathogen (Table 2). Panton-Valentin leukocidin (PVL) was isolated from ten (56\%) S. aureus co-infections, representing 26\% of all co-infections. Among these 18 patients with S. aureus co-infection, 14 had a lung CT 
scan during their ICU stay. Three patients with PVL-positive strain and 1 with PVLnegative strain died before this exam could be performed. Among the 14 patients with CT scan, necrotizing pneumonia was present in 10 patients, 6/7 (86\%) PVL-positive and 4/7 (57\%) PVL-negative ( $p=0.3$ for between groups comparison).

Compared to primary viral pneumonia, co-infected patients had lower BMIs, higher pre-ECMO SOFA scores and received fewer antibiotics before hospitalization (Table 1). No differences were observed for age, co-morbidities, ARDS management before and after ECMO, influenza characteristics (genotype, subtype, neuraminidaseinhibitor use, interval between symptom onset and hospital or ICU admission) and ECMO management (timing of initiation, VV, VA or VAV configuration). When comparing patients with PVL-positive S. aureus co-infection to patients with coinfection due to another pathogen (including PVL-negative S. aureus), no difference were found except that the former had shorter days from symptom onset to hospital admission, ICU admission and oseltamivir treatment. Their outcomes were also not different (Table S3, online supplement).

\subsection{Outcomes}

Among the 77 patients with influenza-associated ARDS requiring ECMO, 42 (55\%) survived to hospital discharge and were alive at 1 year. Comparisons of survivors and non-survivors are reported in Supplementary Table S1. Univariable and multivariable factors associated with in-hospital death are given in Table 3. Multivariable analyses retained: age $>49$ years, ICU admission SAPS II $>70$ and coinfection as independent risk factors for hospital mortality (Table 3). 
Comparisons of the characteristics of patients with documented co-infections and "high” probability of co-infection versus those without or with low probability of coinfection (see Supplementary Table S2) showed co-infection at ICU admission to be associated with in-hospital mortality, and our multivariable analysis retained that association (OR 4.0, 95\% CI 1.3-11.9). Taking into account only the 45 co-infected and highly probable co-infected patients, the prognosis of those having received antibiotics prior to ICU admission was similar to that of those not having received antibiotics (hospital mortality of 54 vs. 61\%, respectively, $\mathrm{p}=0.5$ ).

We then compared the prognosis of the 10 patients with PVL-positive S. aureus co-infection to that of the 8 patients with PVL-negative S. aureus co-infection, and their mortality were similar (hospital mortality of 50\% and 63\%, respectively, $\mathrm{p}=$ $0.6)$.

\section{Discussion}

The results of this study demonstrated that co-infection of influenza-related ARDS patients requiring EMCO was frequent, with S. aureus being the most common pathogen identified. Among the latter, PVL-positive S. aureus strains were frequently responsible. We also found an association between co-infection and mortality, which had never been reported previously for influenza-associated ARDS patients requiring ECMO.

Herein, we confirmed the frequency of co-infection in severe influenza-pneumonia patients. In their recent large study on 2,901 ICU patients in Spain, Martin-Loeches et al. found a 16.6\% co-infection rate [9], whereas Shah et al.’s evaluation of 507 
patients distributed in 33 American centers yielded a rate of 22.5\% [15]. We report a higher co-infection rate than those cited above, which could be explained by multiple factors, e.g., that co-infection could be participating in overall disease severity, as previously advanced [16], the different criteria used to define co-infection, and its diagnosis may have been facilitated by the easier and more reliable sample collection on MV. Only 53\% of Martin-Loeches et al.'s patients were on MV and the vast majority of their patients were already receiving antibiotics [9]. Therefore, some of their co-infected patients might have been missed and misclassified as not coinfected.

Second, we confirmed the independent association of co-infection with poorer outcomes. Although co-infected patients received less frequently antibiotics than patients without co-infection, we think that co-infection directly impact prognosis. As a matter of fact, mortality rate of co-infected and highly probable co-infected patients having received antibiotics prior to admission was similar to that of patients not having received antibiotics prior to admission. Although co-infection was recently shown to be associated with poor outcomes of ICU patients with pneumonia [9], no study had specifically investigated the impact of co-infection on influenza-related ARDS patients requiring ECMO. This point is important because those patients have been described as the best candidates for VV-ECMO support [17]. However, because survival of co-infected ECMO patients described herein was similar to those of severe ARDS patients [18] and previously published series (survival rates ranging from 50 to 87\%) [3,19-21], co-infection should not disqualify a patient with influenza-associated ARDS for ECMO-support.

Third, we documented a high frequency of $S$. aureus co-infection, which is unusual in France and Europe: a French study on severe influenza reported 17\% S. 
aureus co-infections [22], whereas it was $11 \%$ in a recent Spanish study [9].

Streptococcus pneumoniae has usually been the most frequent pathogen recovered from European influenza co-infections, as opposed to higher S. aureus frequency in the US and Australia [8,9,22-24]. That difference between our findings and other European studies might explain the patients' clinical pictures: those with the most severe bacterial co-infections, with a pathogen responsible for severe lung involvement and destruction, e.g., PVL-producing S. aureus, might have the most severe ARDS forms. PVL tropism for damaged lung epithelium is well-demonstrated [25], and results based on small case-series attributed fatal pneumonia to PVL [26], even though its pathogenicity is not clearly understood [27]. However, we did not find any difference in mortality nor in other outcomes between PVL-producing and nonproducing strains. This may be explained by the low number of cases in our study, or by the fact that mortality of these patients with very severe disease is mainly driven by other factors (multi-organ failure, ECMO complications...) rather than the pathogenicity of the bug. Awaiting larger studies on that topic to explore this particular point, we recommend to systematically searching for this microorganism and its toxins in lung samples in patients with influenza-related ARDS.

Our findings, together with the high $P$. aeruginosa rate recently reported [9], may have clinical implications: to date, European recommendations for severe pneumonia do not take into account these particular pathogens, except for specific situations, mainly for patients with risk factors for $P$. aeruginosa [28]. Although the risk of $S$. aureus community-acquired pneumonia is noted in those guidelines as a complication of influenza pneumonia, specific empirical treatment is not specifically recommended. Should our findings be confirmed by others, these pathogens should be considered when choosing empirical antibiotic regimens for specific patients with 
severe pneumonia during the influenza season (i.e., ARDS requiring ECMO or other rescue therapies), for whom direct examination of respiratory secretions yielded Gram-positive cocci, or whose cultures of lower respiratory tract specimens grew $S$. aureus. Perhaps these patients should be started on empirical clindamycin or linezolid, because they suppress PVL production. However, the association between the use of a toxin-suppressing agent and improved outcome has never been demonstrated; therefore, the impact of such a strategy remains to be determined.

Fourth, four patients were diagnosed with Aspergillus fumigatus co-infections. Wauters et al. described nine (23\%) patients with invasive pulmonary aspergillosis complicating severe influenza [29]. In that study, all patients were immunocompromised or taking corticosteroids. More recently, in their retrospective study on 2,901 ICU influenza patients, Martin-Loeches et al. found 7.2\% Aspergillus spp. co-infections [9]. However, the co-morbidities of those patients were not specifically described. Notably, three of our four patients with A. fumigatus coinfections had no pre-existing co-morbidities and did not receive corticosteroids (the fourth had a solid-organ transplant). Thus, physicians should be aware of that specific complication of severe influenza pneumonia, even in non-immunocompromised patients [30].

Our study has several limitations. First, it is a retrospective monocenter study from an ECMO-referral center, thus an obvious selection bias exists and, consequently, our results are difficult to generalize to other centers. Nevertheless, ECMO management impacts outcome (volume effect) [31] and, therefore, the monocenter feature might rather be a strength in this setting. Second, some patients were exposed to antibiotics before ICU admission and might have been misclassified as “no co-infection”. However, analyses of patients with documented and highly 
probable co-infections vs. those without or low probability of co-infection yielded the same results. Third, it would have been interesting to perform molecular biology on lung samples to help identify pathogens and more precisely define, among patients, those with a co-infection vs. those without. Unfortunately, we don't have these data since we don't use this technology on a routine basis in our unit.

\section{Conclusions}

Co-infection of influenza-associated ARDS patients requiring ECMO is frequent, affecting more than half of them, and is independently associated with higher mortality. The epidemiology of pathogens responsible for co-infection seems to be unusual, with a high rate of PVL-producing S. aureus. It remains to be determined whether this pathogen should be taken into account in choosing the initial empirical antimicrobial regimen (use of a PVL-suppressing antibiotic), even in countries with low S. aureus pneumonia rates. Physicians should also be aware of the possibility of early aspergillosis in influenza-associated ARDS patients, even in absence of known risk factors.

\section{Acknowledgements}

The authors thank Janet Jacobson for editorial assistance in revising the manuscript.

\section{Transparency Declaration}

Dr. Luyt reports personal fees from Bayer Healthcare, personal fees from MSD, personal fees from Biomérieux, non-financial support from Curetis, outside the submitted work; and Dr. Combes is the primary investigator of the EOLIA trial 
(NCT01470703), a randomized trial of VV-ECMO, supported in part by MAQUET.

Drs. Bréchot, Lebreton, and Combes have received honoraria for lectures from

MAQUET. The other authors declare that they have no conflicts of interest related to the purpose of this manuscript.

\section{Funding}

None 


\section{References}

[1] Brodie D, Bacchetta M. Extracorporeal membrane oxygenation for ARDS in adults. N Engl J Med 2011;365:1905-14. doi:10.1056/NEJMct1103720.

[2] ESLO Guidelines - adult. http://www.elso.org/Portals/0/IGD/Archive/FileManager/989d4d4d14cusersshy erdocumentselsoguidelinesforadultrespiratoryfailure1.3.pdf (accessed July 10, 2015).

[3] Australia and New Zealand Extracorporeal Membrane Oxygenation (ANZ ECMO) Influenza Investigators, Davies A, Jones D, Bailey M, Beca J, Bellomo R, et al. Extracorporeal Membrane Oxygenation for 2009 Influenza A(H1N1) Acute Respiratory Distress Syndrome. JAMA 2009;302:1888-95. doi:10.1001/jama.2009.1535.

[4] Hodgson CL, Hayes K, Everard T, Nichol A, Davies AR, Bailey MJ, et al. Long-term quality of life in patients with acute respiratory distress syndrome requiring extracorporeal membrane oxygenation for refractory hypoxaemia. Critical Care 2012;16:R202. doi:10.1186/cc11811.

[5] Luyt C-E, Combes A, Becquemin M-H, Beigelman-Aubry C, Hatem S, Brun AL, et al. Long-term outcomes of pandemic 2009 influenza A(H1N1)-associated severe ARDS. Chest 2012;142:583-92. doi:10.1378/chest.11-2196.

[6] Schmidt M, Zogheib E, Rozé H, Repesse X, Lebreton G, Luyt C-E, et al. The PRESERVE mortality risk score and analysis of long-term outcomes after extracorporeal membrane oxygenation for severe acute respiratory distress syndrome. Intensive Care Med 2013;39:1704-13. doi:10.1007/s00134-013$3037-2$.

[7] Schmidt M, Bailey M, Sheldrake J, Hodgson C, Aubron C, Rycus PT, et al. 
Predicting survival after extracorporeal membrane oxygenation for severe acute respiratory failure. The Respiratory Extracorporeal Membrane Oxygenation Survival Prediction (RESP) Score. Am J Respir Crit Care Med 2014;189:137482. doi:10.1164/rccm.201311-2023OC.

[8] Klein EY, Monteforte B, Gupta A, Jiang W, May L, Hsieh Y-H, et al. The frequency of influenza and bacterial coinfection: a systematic review and metaanalysis. Influenza Other Respir Viruses 2016:1-10. doi:10.1111/irv.12398.

[9] Martin-Loeches I, J Schultz M, Vincent J-L, Alvarez-Lerma F, Bos LD, SoléViolán J, et al. Increased incidence of co-infection in critically ill patients with influenza. Intensive Care Med 2017;43:48-58. doi:10.1007/s00134-016-4578-y.

[10] ARDS Definition Task Force, Ranieri VM, Rubenfeld GD, Thompson BT, Ferguson ND, Caldwell E, et al. Acute respiratory distress syndrome: the Berlin Definition. JAMA; 2012;307: 2526-33. doi:10.1001/jama.2012.5669.

[11] ELSO H1N1 Specific Guidelines 2009:1-4. https://www.elso.org/Portals/0/Files/elso\%20h1n1\%20specific\%20guidelines.p df (accessed July 10, 2015)

[12] Luyt C-E, Bréchot N, Demondion P, Jovanovic T, Hekimian G, Lebreton G, et al. Brain injury during venovenous extracorporeal membrane oxygenation. Intensive Care Med 2016;42:897-907. doi:10.1007/s00134-016-4318-3.

[13] de Chambrun MP, Bréchot N, Lebreton G, Schmidt M, Hekimian G, Demondion P, et al. Venoarterial extracorporeal membrane oxygenation for refractory cardiogenic shock post-cardiac arrest. Intensive Care Med 2016:1-9. doi:10.1007/s00134-016-4541-y.

[14] Dangers L, Bréchot N, Schmidt M, Lebreton G, Hekimian G, Nieszkowska A, et al. Extracorporeal membrane oxygenation for acute decompensated heart 
failure. Crit Care Med 2017;vol:1-8. doi:10.1097/CCM.0000000000002485.

[15] Shah NS, Greenberg JA, McNulty MC, Gregg KS, Riddell J IV, Mangino JE, et al. Bacterial and viral co-infections complicating severe influenza: incidence and impact among 507 U.S. patients, 2013-14. J Clin Virol 2016;80:12-9. doi:10.1016/j.jcv.2016.04.008.

[16] Morens DM, Taubenberger JK, Fauci AS. Predominant role of bacterial pneumonia as a cause of death in pandemic influenza: implications for pandemic influenza preparedness. J Infect Dis 2008;198:962-70. doi:10.1086/591708.

[17] Rozencwajg S, Pilcher D, Combes A, Schmidt M. Outcomes and survival prediction models for severe adult acute respiratory distress syndrome treated with extracorporeal membrane oxygenation. Crit Care 2016;20:392. doi:10.1186/s13054-016-1568-y.

[18] Bellani G, Laffey JG, Pham T, Fan E, Brochard L, Esteban A, et al. Epidemiology, patterns of care, and mortality for patients with acute respiratory distress syndrome in intensive care units in 50 countries. JAMA 2016;315:788800. doi:10.1001/jama.2016.0291.

[19] Forrest P, Ratchford J, Burns B, Herkes R, Jackson A, Plunkett B, et al. Retrieval of critically ill adults using extracorporeal membrane oxygenation: an Australian experience. Intensive Care Med 2011;37:824-30. doi:10.1007/s00134-011-2158-8.

[20] Roch A, Hraiech S, Masson E, Grisoli D, Forel J-M, Boucekine M, et al. Outcome of acute respiratory distress syndrome patients treated with extracorporeal membrane oxygenation and brought to a referral center. Intensive Care Med 2014;40:74-83. doi:10.1007/s00134-013-3135-1. 
[21] Schmidt M, Combes A. Influence of ventilatory strategy on the PRESERVE mortality risk score: response to Camporota et al. Intensive Care Med 2014;40:916-6. doi:10.1007/s00134-014-3284-x.

[22] Cuquemelle E, Soulis F, Villers D, Roche-Campo F, Ara Somohano C, Fartoukh M, et al. Can procalcitonin help identify associated bacterial infection in patients with severe influenza pneumonia? A multicentre study. Intensive Care Med 2011;37:796-800. doi:10.1007/s00134-011-2189-1.

[23] Rice TW, Rubinson L, Uyeki TM, Vaughn FL, John BB, Miller RR III, et al. Critical illness from 2009 pandemic influenza A virus and bacterial coinfection in the United States. Critical Care Medicine 2012;40:1487-98. doi:10.1097/CCM.0b013e3182416f23.

[24] Blyth CC, Webb SAR, Kok J, Dwyer DE, van Hal SJ, Foo H, et al. The impact of bacterial and viral co-infection in severe influenza. Influenza Other Respir Viruses 2012;7:168-76. doi:10.1111/j.1750-2659.2012.00360.x.

[25] Loffler B, Niemann S, Ehrhardt C, Horn D. Pathogenesis of Staphylococcus aureus necrotizing pneumonia: the role of PVL and an influenza coinfection. Expert Review of Anti Infect Ther. 2013;11(10):1041-1051

[26] Gillet Y, Issartel B, Vanhems P, Fournet J-C, Lina G, Bes M, et al. Association between Staphylococcus aureus strains carrying gene for Panton-Valentine leukocidin and highly lethal necrotising pneumonia in young immunocompetent patients. The Lancet 2002;359:753-9. doi:10.1016/S0140-6736(02)07877-7.

[27] Peyrani P, Allen M, Wiemken TL, Haque NZ, Zervos MJ, Ford KD, et al. Severity of disease and clinical outcomes in patients with hospital-acquired pneumonia due to methicillin-resistant Staphylococcus aureus strains not influenced by the presence of the Panton-Valentine leukocidin gene. Clin Infect 
Dis 2011;53:766-71. doi:10.1093/cid/cir541.

[28] Woodhead M, Blasi F, Ewig S, Garau J, Huchon G, Ieven M, et al. Guidelines for the management of adult lower respiratory tract infections - Full version. European Society of Clinical Infectious Diseases/New Microbes New Infect 2014;17:E1-E59. doi:10.1111/j.1469-0691.2011.03672.x.

[29] Wauters J, Baar I, Meersseman P, Meersseman W. Invasive pulmonary aspergillosis is a frequent complication of critically ill H1N1 patients: a retrospective study. Intensive Care Med 2012. doi:10.1007/s00134-012-2677-y.

[30] van de Veerdonk FL, Kolwijck E, Lestrade PPA, Hodiamont CJ, Rijnders BJA, van Paassen J, et al. Influenza-associated aspergillosis in critically ill patients. Am J Respir Crit Care Med 2017 (published ahead of print). doi:10.1164/rccm.201612-2540LE.

[31] Combes A, Brodie D, Bartlett R, Brochard L, Brower R, Conrad S, et al. Position paper for the organization of extracorporeal membrane oxygenation programs for acute respiratory failure in adult patients. Am J Respir Crit Care Med 2014;190:488-96. doi:10.1164/rccm.201404-0630CP. 


\section{Figures legend}

Fig. 1. Study flow chart. Abbreviations: ECMO, extracorporeal membrane oxygenation. VA, venoarterial. ARDS, acute respiratory distress syndrome. S. aureus, Staphylococcus aureus. PVL, Panton-Valentin leukocidin) 


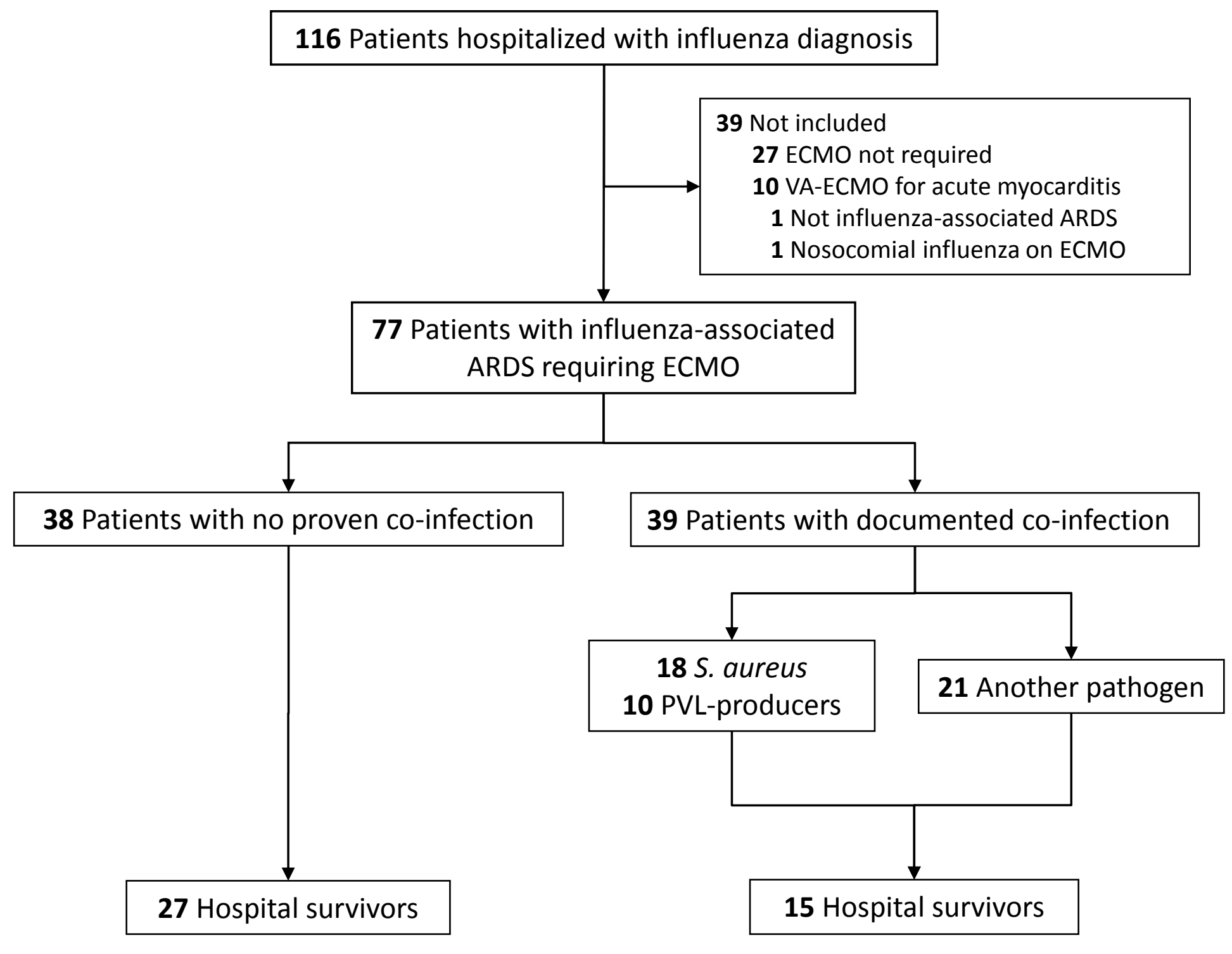




\section{Co-infection with influenza-associated acute respiratory distress syndrome requiring extracorporeal membrane oxygenation}

\section{Online Supplementary material}

Sacha Rozencwajg ${ }^{1,2}$, Nicolas Bréchot ${ }^{1}$, Matthieu Schmidt ${ }^{1,2}$, Guillaume

Hekimian ${ }^{1}$, Guillaume Lebreton ${ }^{3}$, Sebastien Besset ${ }^{1}$, Guillaume Franchineau ${ }^{1}$, Ania Nieszkowska ${ }^{1}$, Pascal Leprince ${ }^{3}$, Alain Combes ${ }^{1,2}$, Charles-Edouard Luyt ${ }^{1,2}$

1) Service de Réanimation, Groupe Hospitalier Pitié-Salpêtrière, Assistance PubliqueHôpitaux de Paris, Paris, France;

${ }^{2)}$ Sorbonne Universités, UPMC Université Paris 06, INSERM, UMRS-1166, ICAN Institute of Cardiometabolism and Nutrition, Paris, France.

${ }^{3)}$ Service de Chirurgie Thoracique et Cardiovasculaire, Institut de Cardiologie, Groupe Hospitalier Pitie-Salpêtrière, Assistance Publique-Hôpitaux de Paris, Paris, France 


\section{Supplemental analysis}

\section{Methods}

When no pathogen was isolated from a patient receiving antibiotics prior to bacteriological sampling, two authors (NB, MS), reviewed all charts to assess whether the patient had a "high" or "low" probability of having a microbial co-infection that might have been missed, based on available clinical, radiological and laboratory findings, including procalcitonin levels when dosages were available. In the case of disagreement between them, a third author (C-EL) arbitrated and classified the patient. In a secondary analysis, patients with microbiologically confirmed coinfection were grouped with those defined as having a "high probability of coinfection", while those with a "low probability of co-infection" were grouped with patients for whom co-infection was ruled out (patients who had received no antibiotics before hospital admission and had negative bacterial samples). Those two groups were compared.

\section{Results}

Results of those supplemental analyses of factors associated with in-hospital mortality grouping patients with documented co-infection and patients with high probability of co-infection versus those of patients not co-infected or with low probability of co-infection are reported in Table S2.

Multivariable analyses retained the following factors as being significantly associated with hospital mortality: age $>49$ years (odds ratio (OR) 5.8, 95\% 
confidence interval (CI) 1.8-18.1), SAPS II >70 (OR 6.5, 95\% CI 2-20.1) and documented or highly probable co-infection (OR 4.0, 95\% CI 1.3-11.9). 
Table S1

Main ICU admission characteristics of all ECMO-treated patients with influenza-associated ARDS: comparisons between hospital survivors and non-survivors

\begin{tabular}{|c|c|c|c|}
\hline Characteristic & $\begin{array}{l}\text { Survivors } \\
(n=42)\end{array}$ & $\begin{array}{l}\text { Non-survivors } \\
(n=35)\end{array}$ & p value \\
\hline Age, years & $41[31-53]$ & $55[43-61]$ & 0.0008 \\
\hline Male sex & $15(36)$ & $23(66)$ & 0.01 \\
\hline Body mass index, $\mathrm{kg} / \mathrm{m}^{2}$ & $31[27-37]$ & 26 [23-30] & $<0.0001$ \\
\hline SOFA score at ICU admission & $8[7-10]$ & $10[8-13]$ & 0.04 \\
\hline SAPS II & $62[55-76]$ & 83 [71-94] & $<0.0001$ \\
\hline Performance status & $0[0-1]$ & $0[0-1]$ & NS \\
\hline \multicolumn{4}{|l|}{ Co-morbidities } \\
\hline Chronic respiratory disease & $2(5)$ & $6(17)$ & NS \\
\hline Immunocompromised & $4(10)$ & $8(23)$ & NS \\
\hline Chronic heart failure & 0 & 0 & - \\
\hline Diabetes mellitus & $4(10)$ & $6(17)$ & NS \\
\hline Chronic renal disease & $1(2)$ & $1(3)$ & NS \\
\hline Chronic liver failure & 0 & 0 & - \\
\hline Peripartum period & $6(14)$ & 0 & 0.03 \\
\hline \multicolumn{4}{|l|}{ ARDS rescue therapies before ECMO } \\
\hline Prone positioning & $27 / 40(68)$ & 20/34 (59) & NS \\
\hline Nitric oxide use & $27 / 40(68)$ & 20/34 (59) & NS \\
\hline Neuromuscular blockades & 37/39 (95) & 31/34 (91) & NS \\
\hline Corticosteroids $^{\mathrm{a}}$ & $5 / 41(12)$ & 6/34 (18) & NS \\
\hline Almitrine use & $3 / 41(7)$ & 1/34 (3) & NS \\
\hline \multicolumn{4}{|l|}{ Blood gases before ECMO start } \\
\hline $\mathrm{pH}$ & $7.22[7.14-7.27]$ & $7.13[7.03-7.25]$ & NS \\
\hline $\mathrm{PaO}_{2} / \mathrm{FIO}_{2}$ ratio, $\mathrm{mm} \mathrm{Hg}$ & $53[46-66]$ & $64[45-76]$ & NS \\
\hline Lactate $(\mathrm{mmol} / \mathrm{L})$ & $2.8[1.8-5.2]$ & $4[1.3-7.8]$ & NS \\
\hline SOFA score before ECMO start & $12[9-15]$ & $16[14-20]$ & $<0.0001$ \\
\hline \multicolumn{4}{|l|}{ ECMO management } \\
\hline $\begin{array}{l}\text { Days from MV to ECMO initiation } \\
\text { ECMO type }\end{array}$ & $2[1-8]$ & $2[1-8]$ & NS \\
\hline VV-ECMO & $37(88)$ & $21(60)$ & 0.007 \\
\hline VA- or VAV-ECMO & $5(12)$ & $14(40)$ & 0.007 \\
\hline $\begin{array}{l}\text { ECMO implanted by mobile ECMO team } \\
\text { Reason for ECMO }\end{array}$ & $38(90)$ & $30(86)$ & NS \\
\hline Refractory hypoxemia & $38(90)$ & $24(69)$ & 0.02 \\
\hline Uncompensated hypercapnia & $1(2)$ & 0 & NS \\
\hline Septic shock & 0 & $6(17)$ & NS \\
\hline Cardiogenic shock & $3(7)$ & $5(14)$ & NS \\
\hline
\end{tabular}

Abbreviations: ICU, intensive care unit; ECMO, extracorporeal membrane oxygenation; ARDS, acute respiratory distress syndrome; SOFA, Sequential Organ-Failure Assessment; SAPS II, Simplified Acute Physiology Score II; NS, nonsignificant; MV, mechanical ventilation; VV, venovenous; VA, venoarterial: VAV, venoarterialvenous.

Continuous variables, expressed as mean \pm SD or median [IQR], were compared using Student's $t$-test or Wilcoxon's rank test. Categorical variables, expressed as $n(\%)$,were 
compared with $\chi^{2}$ tests.

${ }^{\text {a }}$ Dose $>1 \mathrm{mg} / \mathrm{kg} /$ day. 
Table S2

Main ICU-admission characteristics of all ECMO-treated influenza-associated ARDS patients: comparisons between patients with "not co-infected + low probability of co-infection" (No + Low) and "co-infected + high probability of co-infection" (Yes + High)

\begin{tabular}{lllll}
\hline Characteristic & $\begin{array}{l}\text { All patients } \\
(n=77)\end{array}$ & $\begin{array}{l}\text { No + Low } \\
(n=32)\end{array}$ & $\begin{array}{l}\text { Yes + High } \\
(n=45)\end{array}$ & p value \\
\hline Age, years & $49[36-58]$ & $45[35-58]$ & $50[38-58]$ & NS \\
Male sex & $38(49)$ & $10(31)$ & $28(62)$ & 0.01 \\
Body mass index, kg/m ${ }^{2}$ & $28.7[25.2-33.5]$ & $32.6[27.8-38.8]$ & $27.4[24.0-29.9]$ & $<0.0001$ \\
SOFA score at ICU admission & $8[8-12]$ & $8[5-8]$ & $10[8-13]$ & 0.0003 \\
SAPS II & $74[60-83]$ & $65[54-77]$ & $78[63-89]$ & 0.004 \\
Co-morbidities, & & & & NS \\
Chronic respiratory disease & $8(10)$ & $4(13)$ & $4(9)$ & NS \\
Immunocompromised & $12(16)$ & $3(9)$ & $9(20)$ & - \\
Chronic heart failure & 0 & 0 & 0 & NS \\
Diabetes mellitus & $10(13)$ & $3(9)$ & $7(16)$ & NS \\
Chronic renal disease & $2(3)$ & 0 & $2(4)$ & - \\
Chronic liver failure & 0 & 0 & 0 & NS \\
Peripartum period & $6(8)$ & $5(16)$ & $4(2)$ & NS \\
Days from symptom onset to hospital admission & $4[3-6]$ & $4[3-7]$ & $0[0-1]$ & NS \\
Days from hospitalization to ICU admission & $0[0-1]$ & $0[0-1]$ & & NS \\
Rescue therapies before ECMO & & & $29 / 43(67)$ & NS \\
Prone positioning & $47 / 74(64)$ & $18 / 31(58)$ & $27 / 43(63)$ & NS \\
Nitric oxide use & $47 / 74(64)$ & $20 / 31(65)$ & $42 / 43(98)$ & NS \\
Neuromuscular blockades & $68 / 73(93)$ & $26 / 30(87)$ & $8 / 44(18)$ & NS \\
Corticosteroids & $11 / 75(15)$ & $3 / 31(10)$ & $2 / 44(5)$ & \\
Almitrine use & $4 / 75(5)$ & $2 / 31(6)$ & & \\
Blood gases before ECMO start & & & &
\end{tabular}




\begin{tabular}{|c|c|c|c|c|}
\hline $\mathrm{pH}$ & $7.19[7.08-7.25]$ & $7.18[7.04-7.28]$ & $7,19[7.14-7.24]$ & NS \\
\hline $\mathrm{PaO}_{2} / \mathrm{FIO}_{2}$ ratio, $\mathrm{mm} \mathrm{Hg}$ & $54[46-71]$ & $54[45-68]$ & $55[47-76]$ & NS \\
\hline Lactate, $\mathrm{mmol} / \mathrm{L}$ & $3.3[1.7-6]$ & $2.7[1.7-7.2]$ & $3.5[1.9-6]$ & NS \\
\hline SOFA score at ECMO start & $14[11-17]$ & $12[9-16]$ & $16[14-16]$ & 0.0002 \\
\hline \multicolumn{5}{|l|}{ ECMO management } \\
\hline Days from MV to ECMO initiation & $2[1-8]$ & $2[1-7]$ & 2 [1-9] & NS \\
\hline \multicolumn{5}{|l|}{ ECMO type } \\
\hline VV-ECMO & $58(75)$ & $27(84)$ & 31 (69) & NS \\
\hline VA- or VAV-ECMO & $19(25)$ & $5(16)$ & $14(31)$ & NS \\
\hline ECMO implanted by mobile ECMO team & $68(88)$ & $26(81)$ & $42(93)$ & NS \\
\hline \multicolumn{5}{|l|}{ Reason for ECMO } \\
\hline Refractory hypoxemia & $62(81)$ & $28(88)$ & $34(76)$ & NS \\
\hline Uncompensated hypercapnia & $1(1)$ & $1(3)$ & 0 & NS \\
\hline Septic shock & $6(8)$ & $1(3)$ & $5(11)$ & NS \\
\hline Cardiogenic shock & $8(10)$ & $2(6)$ & $6(13)$ & NS \\
\hline \multicolumn{5}{|l|}{ Influenza characteristics } \\
\hline Influenza A & $69(90)$ & $31(97)$ & $38(84)$ & NS \\
\hline 2009v(H1N1) & $65(84)$ & $30(94)$ & $35(78)$ & NS \\
\hline H3N2 & $2(3)$ & 0 & $2(4)$ & NS \\
\hline No subtype & $2(3)$ & $1(3)$ & $1(2)$ & NS \\
\hline Influenza B & $8(10)$ & $1(3)$ & $7(16)$ & NS \\
\hline \multicolumn{5}{|l|}{ Neuraminidase inhibitors } \\
\hline Oseltamivir & $71(92)$ & $28(88)$ & $43(96)$ & NS \\
\hline Days from symptom onset to oseltamivir & $6[4-9]$ & $7[5-9]$ & 5 [3-9] & NS \\
\hline Zanamivir & $2(3)$ & 0 & $2(4)$ & NS \\
\hline \multicolumn{5}{|l|}{ Antibiotics } \\
\hline Antibiotics before hospital admission & $28(36)$ & $15(47)$ & $13(29)$ & NS \\
\hline Amoxicillin & $11 / 28(39)$ & $3(9)$ & $8(18)$ & \\
\hline
\end{tabular}


Amoxicillin-clavulanate

$1^{\text {st }}$-generation cephalosporin

$3^{\text {rd }}$-generation cephalosporin

Macrolide

Characteristics of ICU hospitalization

Renal replacement therapy

Cardiogenic shock

Neurological event

Major hemolysis

Cardiac arrest

Major bleeding event

In-hospital mortality

ECMO and MV outcomes

ECMO duration

ECMO-free days $^{\mathrm{d}}$

MV duration, days

MV-free days ${ }^{\mathrm{d}}$

Hospitalization outcomes

$$
\text { ICU LOS, days }
$$

Hospital LOS, days

$\begin{array}{llll}7 / 28(25) & 4(13) & 3(7) & \\ 2 / 28(7) & 2(6) & 0 & \\ 4 / 28(14) & 4(13) & 0 & \\ 4 / 28(14) & 2(6) & 2(4) & \\ & & & \text { NS } \\ 53(69) & 18(56) & 35(78) & \text { NS } \\ 15(19) & 3(9) & 12(27) & \text { NS } \\ 5(6) & 2(6) & 3(7) & \text { NS } \\ 8(10) & 4(13) & 4(9) & \text { NS } \\ 7(9) & 4(13) & 3(7) & 0.01 \\ 29(38) & 12(38) & 17(38) & \\ 35(45) & 9(28) & 26(58) & \text { NS } \\ 22[11-41] & 19[8-34] & 12[5-32] & 0.003 \\ 0[0-40] & 27[0-47] & 0[0-24] & \text { NS } \\ 37[22-66] & 27[12-50] & 24[11-48] & 0.002 \\ 0[0-3] & 0[0-14] & 0[0-0] & \\ 28[12-52] & 28[14-51] & 29[12-53] & \text { NS } \\ 35[14-78] & 41[21-78] & 30[11-81] & \text { NS }\end{array}$

Abbreviations: ICU, intensive care unit; ECMO, extracorporeal membrane oxygenation; ARDS, acute respiratory distress syndrome; SOFA, Sequential Organ-Failure Assessment; SAPS II, Simplified Acute Physiology Score II; MV, mechanical ventilation; VV, venovenous; VA, venoarterial: VAV,

venoarterialvenouus; LOS, length of stay.

Continuous variables, expressed as mean \pm SD or median [IQR], were compared using Student's $t$-test or Wilcoxon's rank test. Categorical variables, expressed as $n(\%)$, were compared with $\chi^{2}$ tests.

${ }^{a}$ Dose $>1 \mathrm{mg} / \mathrm{kg} /$ day.

${ }^{\mathrm{b}}$ Blood gases were available for 46 patients.

${ }^{\mathrm{d}}$ Calculated from day 1 (ECMO start) to day 60. 
Table S3

Main ICU-admission characteristics of bacteriologically-confirmed co-infected patients: comparisons between patients with PVL-positive strains of S. aureus and other co-infections

\begin{tabular}{|c|c|c|c|}
\hline Characteristic & $\begin{array}{l}\text { All patients } \\
\quad(n=39)\end{array}$ & $\begin{array}{l}\text { PVL producer } \\
\text { S. aureus } \\
\quad(n=10)\end{array}$ & $\begin{array}{c}\text { Other pathogens } \\
\qquad(n=29)\end{array}$ \\
\hline Age, years & $51[39-58.75]$ & 39.5 [27-57] & $52[41.5-59.5]$ \\
\hline Male sex & $22(56)$ & $3(30)$ & $19(65.5)$ \\
\hline Body mass index, $\mathrm{kg} / \mathrm{m}^{2}$ & 26.25 [23.60-29.47] & 24.16 [22.59-29.39] & $27.5[24.5-30.29]$ \\
\hline SOFA score at ICU admission & $16[13.25-18]$ & $17.5[14-22]$ & 15 [12.75-18] \\
\hline SAPS II & $77[62-87.5]$ & $82.5[76-88]$ & 73 [60.75-86.25] \\
\hline \multicolumn{4}{|l|}{ Co-morbidities, } \\
\hline Chronic respiratory disease & $3(8)$ & $1(10)$ & $2(7)$ \\
\hline Immunocompromised & $7(18)$ & $1(10)$ & $6(21)$ \\
\hline Chronic heart failure & 0 & 0 & 0 \\
\hline Diabetes mellitus & $6(15)$ & $1(10)$ & $5(17)$ \\
\hline Chronic renal disease & $1(3)$ & 0 & $1(3)$ \\
\hline Chronic liver failure & 0 & 0 & 0 \\
\hline Peripartum period & $1(3)$ & $1(10)$ & 0 \\
\hline Days from symptom onset to hospital admission ${ }^{\mathrm{b}}$ & $4[2.25-5]$ & $3[1-3]$ & $5[2.75-6]$ \\
\hline Days from hospitalization to ICU admission ${ }^{\mathrm{b}}$ & $0[0-1]$ & $0[0-1]$ & $0[0-1]$ \\
\hline \multicolumn{4}{|l|}{ Influenza characteristics } \\
\hline Influenza A & $32(82)$ & $8(80)$ & $24(83)$ \\
\hline 2009v(H1N1) & $29(76)$ & $7(70)$ & $22(79)$ \\
\hline H3N2 & $2(5)$ & $1(10)$ & $1(4)$ \\
\hline No subtype available & $7(18)$ & $2(20)$ & $5(18)$ \\
\hline Influenza B & $7(18)$ & $2(20)$ & $5(17)$ \\
\hline
\end{tabular}


Neuraminidase inhibitors

Zanamivir

Antibiotics

Antibiotics before hospital admission

Amoxicillin

Amoxicillin-clavulanate

Macrolide

Characteristics of ICU hospitalization

Necrotizing pneumonia ${ }^{c}$

Renal replacement therapy

Cardiogenic shock

Neurological event

Major hemolysis

Cardiac arrest

Major bleeding event

In-hospital mortality

ECMO and MV outcomes

\section{ECMO duration}

ECMO-free days $^{\mathrm{d}}$

MV duration, days

MV-free days ${ }^{\mathrm{d}}$

Hospitalization outcomes

ICU LOS, days

Hospital LOS, days
37 (95)

5 [3-8]

2 (5)

$10(100)$

3 [3-4]

1 (10)

1 (10)

1 (10)

0

2 (5)

2 (5)

$$
\begin{gathered}
10 / 14(71) \\
30(77) \\
10(26) \\
3(8) \\
3(8) \\
2(5) \\
14(36) \\
24(61.5)
\end{gathered}
$$
9 [2.75-29.75]
0 [0-19]
17 [10-39]
0 [0-0]

22 [11.25-49]

25.5 [12-77]
27 (93)

6 [4-7.75]

1 (3)

9 (31)

4 (14)

2 (7)

$2(7)$

4/7 (57)

$22(76)$

8 (28)

3 (10)

2 (7)

2 (7)

10 (34)

19 (65.5)

8 [2-27.5]

0 [0-1.75]

17 [11.5-34]

0 [0-0]

19 [12-47]

23 [12.5-73.5] 
Abbreviations: PVL, Panton-Valentine Leukocidin; ICU, intensive care unit; ECMO, extracorporeal membrane oxygenation; ARDS, acute respiratory distress syndrome; SOFA, Sequential Organ-Failure Assessment; SAPS II, Simplified Acute Physiology Score II; MV, mechanical ventilation; LOS, length of stay.

Continuous variables, expressed as mean \pm SD or median [IQR], were compared using Student's $t$-test or Wilcoxon’s rank test. Categorical variables, expressed as $n(\%)$, were compared with $\chi^{2}$ tests.

a Including 8 patients with non-PVL producers $S$. aureus co-infection

${ }^{\mathrm{b}} \mathrm{p}<0.05$

c Among patients with S. aureus co-infection. 4 out of 18 had no CT scan (3 with PVL, 1 without), thus the information is not available

${ }^{\mathrm{d}}$ Calculated from day 1 (ECMO start) to day 60. 